\title{
Remote physiological monitoring: Clinical, financial, and behavioral outcomes in a heart failure population
}

\author{
Laurel R. Hudson MSN, RN \\ American Healthways, Nashville \\ G. Brent Hamar DDS, MPH \\ American Healthways, Nashville \\ Patty Orr RN, EdD \\ American Healthways, Nashville \\ Jeffrey H. Johnson BS \\ American Healthways, Nashville \\ Follow this and additional works at: https://jdc.jefferson.edu/healthpolicyfaculty \\ iny Neftzger MA \\ Amertcan thealthwalths, Servisinesillesearch Commons \\ Let us know how access to this document benefits you
}

\section{See next page for additional authors}

\section{Recommended Citation}

Hudson, Laurel R. MSN, RN; Hamar, G. Brent DDS, MPH; Orr, Patty RN, EdD; Johnson, Jeffrey H. BS; Neftzger, Amy MA; Chung, Richard S. MD; Williams, Myra L. MPH; Gandy, William M. EdD; Crawford, Albert PhD, MBA, MSIS; Clarke, Janice I. RN, BBA; and Goldfarb, Neil I., "Remote physiological monitoring: Clinical, financial, and behavioral outcomes in a heart failure population" (2005). College of Population Health Faculty Papers. Paper 28.

https://jdc.jefferson.edu/healthpolicyfaculty/28

This Article is brought to you for free and open access by the Jefferson Digital Commons. The Jefferson Digital Commons is a service of Thomas Jefferson University's Center for Teaching and Learning (CTL). The Commons is a showcase for Jefferson books and journals, peer-reviewed scholarly publications, unique historical collections from the University archives, and teaching tools. The Jefferson Digital Commons allows researchers and interested readers anywhere in the world to learn about and keep up to date with Jefferson scholarship. This article has been accepted for inclusion in College of Population Health Faculty Papers by an authorized administrator of the Jefferson Digital Commons. For more information, please contact: JeffersonDigitalCommons@jefferson.edu. 


\section{Authors}

Laurel R. Hudson MSN, RN; G. Brent Hamar DDS, MPH; Patty Orr RN, EdD; Jeffrey H. Johnson BS; Amy Neftzger MA; Richard S. Chung MD; Myra L. Williams MPH; William M. Gandy EdD; Albert Crawford PhD, MBA, MSIS; Janice I. Clarke RN, BBA; and Neil I. Goldfarb 


\title{
Remote Physiological Monitoring: Clinical, Financial, and Behavioral Outcomes in a Heart Failure Population
}

\author{
LAUREL R. HUDSON, M.S.N., R.N. ${ }^{1}$ G. BRENT HAMAR, D.D.S., M.P.H., ${ }^{1}$ \\ PATTY ORR, R.N., Ed.D., ${ }^{1}$ JEFFREY H. JOHNSON, B.S., ${ }^{1}$ AMY NEFTZGER, M.A., ${ }^{1}$ \\ RICHARD S. CHUNG, M.D., ${ }^{1}$ MYRA L. WILLIAMS, M.P.H., ${ }^{1}$ WILLIAM M. GANDY, Ed.D., ${ }^{1}$ \\ ALBERT CRAWFORD, Ph.D., M.B.A., M.S.I.S., ${ }^{2}$ JANICE CLARKE, R.N., B.B.A., ${ }^{2}$ \\ and NEIL I. GOLDFARB ${ }^{2}$
}

\begin{abstract}
This article reports on the outcomes associated with remote physiological monitoring (RPM) conducted as part of a heart failure disease management program. Claims data, medical records, data transmission records, and survey results for 91 individuals ages 50-92 (mean 74 years) successfully completing a heart failure RPM program were analyzed for time periods before, during, and after the monitoring intervention. The program was associated with significant reductions in per member per month costs and emergency room and hospital utilization. More detailed analyses were performed for specific gender and age subgroups. Participant surveys indicated high levels of satisfaction, and improvements in self-perceived health status, self-efficacy, and self-management behaviors. This study is the first to assess the impact of a RPM program following removal of the monitoring equipment. The results indicate that RPM, as a component of a traditional disease management program, has a sustained, beneficial effect on participants' lifestyles after the monitoring period has ended. (Disease Management 2005;8:379-381)
\end{abstract}

\section{INTRODUCTION}

I $\mathrm{N}$ THE PAST 30 YEARS, the prevalence of heart failure (HF) in the United States has grown by $500 \% .{ }^{1}$ As the elderly population continues to expand, and as persons with HF live longer, the potential cost and burden to society is enormous. ${ }^{1}$

$\mathrm{HF}$ is one of the most fatal and costly chronic diseases affecting the elderly. With greater than 700,000 hospitalizations for Medicare beneficiaries each year, it accounts for more admissions than any other elderly diagnosis. ${ }^{2}$ Readmissions also are prevalent among those with HF, with $78 \%$ of patients having at least two hospital admissions per year. ${ }^{3}$ Fifty percent of HF patients have three or more comorbidities, ${ }^{3}$ and these patients take an average of six medications at any given time. ${ }^{4}$ Costs of $\mathrm{HF}$ are high, with an average of $\$ 7863$ per hospitalization, ${ }^{5}$ an average of $\$ 438$ per month for HF medications, ${ }^{6}$ and total annual direct and indirect costs to the U.S. healthcare system of $\$ 27.9$ billion. $^{7}$

These high cost and utilization figures can be

\footnotetext{
${ }^{1}$ American Healthways, Nashville, Tennessee.

${ }^{2}$ Department of Health Policy, Jefferson Medical College, Philadelphia, Pennsylvania.
} 
attributed in part to gaps in quality of care for HF patients. For instance, despite evidence showing that beta-blockers and angiotensinconverting enzyme inhibitors (ACE-I) can significantly decrease morbidity and mortality of congestive heart failure (CHF) patients, the rates of prescription are low, $18 \%$ and $38 \%$ (for beta-blockers and ACE-I, respectively). ${ }^{5}$ A study of academic medical centers found that opportunities for improvement existed in ACE-I dosing as well as in patient education regarding the importance of monitoring daily weights, and in smoking cessation. ${ }^{8}$

An estimated $20 \%$ of hospitalizations for $\mathrm{HF}$ (representing $\$ 2.72$ billion in total costs) could be prevented through improvements in medical management and patient self-management (ie, lifestyle changes and adherence to medications). ${ }^{8}$ The disease management (DM) industry has identified opportunities for improvement in quality of care and outcomes for HF. Industry initiatives target both providers and patients, with the dual goals of improving clinical outcomes while decreasing avoidable utilization. Numerous studies of HF DM programs have demonstrated improvements including decreased hospitalizations, improved prescribing patterns (improved use and dose of betablockers and ACE-I), decreased costs, and shorter lengths of stay. ${ }^{9-11}$

Certain HF DM programs have enhanced their interventions by incorporating remote physiological monitoring (RPM). Studies citing use of remote monitoring yield ambiguous results; some have reported improved outcomes such as reduced mortality, decreased utilization, and lower hospital charges, ${ }^{12-14}$ while others have found no differences when the RPM component is taken into account. ${ }^{14}$

The purpose of this study was to examine the effect of RPM in a HF DM population during and after the monitoring period. While previous studies have examined the effect of remote monitoring on outcomes, as noted above, none have captured the impact of such a program on the utilization and health status of HF patients after the monitoring phase had concluded. This study evaluates the initial impact and the longterm effects of RPM in a HF population by examining data both during and after "graduation" from such a program.

\section{METHODS}

\section{Program description}

Participants in this study are a subset of members enrolled in a standard HF DM program. For inclusion in the standard program, health plan members are identified via a specific algorithm using HF ICD-9 diagnosis codes. Identified members and their primary care physicians receive letters explaining the details and goals of the program, emphasizing that the program supports the physician's plan of care for his or her health plan members with HF. Standard HF program members routinely receive written materials describing the standards of care for HF as well as regular calls from a registered nurse (RN). Common interventions by the $\mathrm{RN}$ during the care calls include teaching the participant to: assess for signs and symptoms of worsening HF, selfmonitor for potential exacerbations, and use physician-directed strategies to prevent exacerbations. Evidence-based HF medications, blood pressure (BP) control, and appropriate nutritional therapy are reviewed. Members also are assisted in developing a goal and determining the appropriate actions to take for optimal management of their illness, for example: eating a low sodium diet, routinely taking and monitoring blood pressure, and monitoring weight on a daily basis.

When claims data indicate instability of a participant's HF, he or she is considered for placement in the RPM program. Selection for the RPM program is made on the basis of meeting one of the following criteria: two HF-related hospitalizations in the past 12 months, two HF-related emergency department visits in the past 12 months, or one of each of the aforementioned within a 12-month period. Clinicians may refer members to the RPM program, particularly those who are not monitoring their symptoms daily or are displaying other signs of non-adherence to optimal self-management (eg, lack of willingness to follow restricted sodium in diet or lack of compliance to medication regimen).

Participants in the RPM program receive a scale, a BP machine, and an electronic "hub" for transmitting weight and BP data via their 
home telephone lines to clinicians in a Care Enhancement Center (CEC). These clinical data, transmitted by the participant on a daily basis, are uploaded into an electronic medical record and compared with previous values. If the data violate predetermined alert parameters, the system prompts CEC clinicians to call the participant and discuss current signs and symptoms. In this way, the clinicians guide participants in taking actions to better control the symptoms of their HF.

Graduation from the RPM program occurs when the participants are: following a low sodium diet, weighing daily, demonstrating an ability to correctly verbalize what they need to do if symptoms change or worsen, and maintaining stable vital signs. When remote monitoring is discontinued, the participant receives a graduation packet containing instructions, a home monitoring $\log$, and a coupon for a battery-operated scale.

Over the past three years, 4,103 members with HF have participated in the standard HF DM program. Of these, 852 have participated in the RPM program. This study sample consisted of the first 93 "graduates" of the RPM program who were followed subsequently for 6 months while enrolled in the standard HF DM program.

RPM has intrinsic value as a tool for early identification of worsening physiological profiles, enabling clinicians to take corrective measures before patients require emergency care or hospitalization. In the context of this program, the ultimate goal of RPM is to initiate and sustain positive self-care behavior change among individuals with HF. By undergoing daily selfmonitoring of weight and blood pressure, individuals become aware of behaviors that contribute to fluctuations in weight and blood pressure. Once these behaviors are identified, individuals learn to restrict or monitor them to prevent further "alarm" situations from occurring. Previous literature has shown that men and women differ in their malleability to behavior change initiatives. ${ }^{15-17}$ Accordingly, this study seeks to delineate whether, and to what extent, various gender and age subgroups may be more or less responsive to these types of techniques so that intensive resources such as remote monitoring can be applied most efficiently and effectively.

\section{Sample description}

Subjects were identified through analysis of database records of graduation from the RPM program. Only those participants who graduated were included in this study, to ensure the availability of data for the baseline, monitoring, and 6-month follow-up periods. A total of 93 members graduated from the remote monitoring program; after two exclusions (described below), 91 were included in the study. Data were obtained from four sources: medical claims, electronic medical records from the DM clinical information system, home monitoring equipment data transmissions, and a telephone survey.

Age and gender. A total of 93 male and female subjects, ages 50-92 (at graduation), were initially enrolled in this study. Two participants, one male and one female, were excluded on the basis of clinical criteria (claims with ICD-9 diagnoses unrelated to HF which resulted in financial per member per month (PMPM) costs more than four standard deviations from the mean for this group.) Forty-seven percent of the sample was female $(n=43)$, and $53 \%$ was male $(n=48)$. The mean age was 74 . Average female age was 76 years, while average male age was 73 years. Individuals were classified into one of three age groups for analysis: 50-64, 65-79, or 80-92.

A comparison of the graduates $(n=91)$ studied with the remainder of the population $(n=$ 736) shows no difference by gender (chisquare $=0.87, \mathrm{df}=1, p=$ n.s.) or age group (chi-square $=7.735, \mathrm{df}=3, p=$ n.s.). However, the difference by age group approaches statistical significance (7.735 vs. a critical value of 7.815); for example, while $27.4 \%$ of those not included in the study sample were under age 65 , only $15.4 \%$ of sample members were under 65 . Thus, some caution should be used in generalizing the results by age group.

Burden of illness. It is well established in the health care research literature that males and females have different utilization patterns. Additionally, individuals with greater illness burdens tend toward heavier healthcare utilization. Because of the small sample size and the slight 
imbalance in the gender distribution, the authors sought to assess potential differences in illness burden between males and females prior to the intervention phase to determine the potential impact of this imbalance on study findings. To examine gender differences in preintervention morbidity levels, adjusted clinical groups (ACGs) were calculated based on the claims data for the year prior to the intervention phase to obtain the relative weights for each group. The relationship between gender and mean relative weight (case-mix index) was assessed through a one-way analysis of variance (ANOVA). The result of the ANOVA was a nonsignificant $F$ value $(F=1.06)$, suggesting that the males and females in the study were not substantially different in terms of illness burden prior to the intervention phase of the study.

\section{Data collection}

As noted above, data were collected from four sources: insurance claims, DM program electronic medical records, RPM data transmission records, and a post-graduation survey.

Insurance claims data. Inpatient, outpatient, and pharmacy claims were examined for RPM program participants. The claims were sorted by date and aggregated to generate totals for the pre-monitoring, monitoring, and post-monitoring periods. Because length of coverage by the insurer varied among participants, the "pre-RPM" claim period was standardized by limiting it to the 12 months prior to the RPM start date. All claims from the RPM start date through the RPM graduation date were classified as "during the RPM claim period"; for eight study participants, monitoring lasted for only 8-11 months; for all other study participants, monitoring lasted 12 months or longer, but only the first 12 months of data were analyzed. All claims dated after the participant's RPM graduation were classified as "post-RPM claim period"; the average time off of remote monitoring was 5.8 months.

The cost metric, calculated for each of the three time periods, was average PMPM costs. The three utilization metrics, calculated for each of the three time periods, included emer- gency room (ER) visits per thousand memberyears, hospital admissions per thousand member-years, and hospital readmissions (within 60 days post discharge) per thousand memberyears. Student $t$-tests were performed to determine the statistical significance of comparisons of PMPM costs between the pre-RPM and RPM claim periods and between the pre-RPM and post-RPM periods. Chi-square tests for equivalence of person-time rates were performed to evaluate the statistical significance of changes in all three measures of utilization between the pre-RPM and post-RPM periods. Metrics were calculated and analyses were conducted for the entire group for all three time periods. Then, additional subgroup analyses examined changes in the three measures of utilization for the six gender-age subgroups.

DM program medical records. Clinical data, demographic data (age and gender), and program data (monitoring start date and graduation date) were retrieved from participants' electronic medical records, which nurses used to record interactions with participants.

RPM data transmission records. The RPM equipment provides electronic transmission of weight, $\mathrm{BP}$, and pulse readings to the nurse call center on a daily basis. Parameters are set to define the "safe" range and, when readings occur outside of this range, alerts are triggered. Monitoring alert data were extracted from the electronic clinical information system and examined by type of alert (ie, change in systolic $\mathrm{BP}$, change in diastolic $\mathrm{BP}$, or change in weight). The proportion of participants having no alerts during their first month of home monitoring was compared with the proportion having no alerts during the last month of monitoring, for all three types of alerts. The statistical significance of these changes over time was evaluated using chi-square tests.

Survey data. A postgraduation survey was developed to assess the impact of the RPM program on the participants' perceived health status and health behavioral habits. The questions, developed in conjunction with a cardiologist and other cardiac and RPM clinical experts, were designed to assess such constructs as per- 
ceived severity of current condition, whether or not the member had access to a method for daily weighing, whether or not the member continued to engage in daily weighing after graduation, perception of "empowerment," use of diuretic (or change in use), whether or not the member had an action plan, current symptom evaluation, whether or not the member engaged in smoking cessation, and whether the implementation of other behavioral health improvements had taken place during the home monitoring period. The survey was content validated and administered telephonically by a CEC nurse approximately three months after participants' graduation from the RPM program.

\section{RESULTS}

\section{PMPM}

The 91 participants experienced a significant $(p=0.04)$ reduction in PMPM costs during the 8 to 12 -month period on home monitoring (average \$629.79) when compared to PMPM costs in the pre-RPM period (average $\$ 1,002.81$; Table 1). Participant claims from the post-monitoring period revealed a further decrease in PMPM costs (average $\$ 508.54 ; p=0.02$ ) when compared to the pre-RPM period.

\section{Utilization}

As shown in Table 2, cost savings were derived from decreased rates of emergency visits, hospital admissions, and readmissions during remote monitoring and after removal of the monitor. Emergency visits per thousand member-years dropped from 1013.8 pre-RPM to 633.1 during RPM and to 573.6 post-RPM; the pre- to post-monitoring reduction was significant $(p=0.01)$. Admissions per thousand member-years dropped from 705.2 pre-RPM to 429.4 during RPM and to 321.2 post-RPM (preto post-monitoring decrease significance: $p<$ 0.01). And, readmissions for HF within 60 days also decreased, from 143.3 per thousand member-years pre-RPM to 72.8 during monitoring and to 22.9 post-RPM (pre- to post-monitoring decrease significance: $p=0.04$ ).

Examining utilization trends by gender and age group, emergency visits per thousand member-years showed decreases between the pre-RPM and the post-RPM period in five out of six comparisons (Table 3). However, the decrease was statistically significant only for the youngest males (ages 50-64, $p=0.034$ ). The only group where there was an apparent (but nonsignificant) rise in emergency visits was females ages 65-79.

Overall, hospital admissions per thousand member-years showed decreases from the preRPM period to the post-RPM period for five out of six comparisons by gender and age group (Table 4). As with emergency visits, the decrease reached statistical significance only for males ages $65-79(p=0.031)$. The only exception to the downward trend in admissions was the rise in admissions among females ages 65-79, also matching the pattern for emergency visits.

Turning to readmissions within 60 days, while there were no statistically significant differences, the pattern was the same as for emer-

\begin{tabular}{|c|c|c|c|c|c|c|}
\hline PMPM & $\mathrm{N}$ & $\begin{array}{c}\text { Pre-RPM } \\
\text { mean } \\
\quad(S D)\end{array}$ & $\begin{array}{c}\text { During-RPM } \\
\text { mean } \\
(S D)\end{array}$ & Pre to during & $\begin{array}{l}\text { Post-RPM } \\
\text { mean } \\
(S D)\end{array}$ & Pre to post \\
\hline Males & 48 & $\begin{array}{c}\$ 947.92 \\
(\$ 1849.5)\end{array}$ & $\begin{array}{c}\$ 675.86 \\
(\$ 782.5)\end{array}$ & $\begin{aligned} t & =1.36 \\
\mathrm{df} & =47 \\
p & =0.18\end{aligned}$ & $\begin{array}{c}\$ 485.42 \\
(\$ 577.2)\end{array}$ & $\begin{aligned} t & =1.76 \\
\mathrm{df} & =47 \\
p & =0.08\end{aligned}$ \\
\hline Females & 43 & $\begin{array}{l}\$ 1,064.45 \\
(\$ 2232.2)\end{array}$ & $\begin{array}{c}\$ 579.81 \\
(\$ 691.1)\end{array}$ & $\begin{aligned} t & =1.62 \\
\mathrm{df} & =42 \\
p & =0.11\end{aligned}$ & $\begin{array}{r}\$ 535.17 \\
(\$ 1225.5)\end{array}$ & $\begin{aligned} t & =1.51 \\
\mathrm{df} & =42 \\
p & =0.14\end{aligned}$ \\
\hline Overall & 91 & $\begin{array}{l}\$ 1,002.81 \\
(\$ 2028.6)\end{array}$ & $\begin{array}{c}\$ 629.79 \\
(\$ 736.7)\end{array}$ & $\begin{aligned} t & =2.12 \\
\mathrm{df} & =90 \\
p & =0.04\end{aligned}$ & $\begin{array}{c}\$ 508.54 \\
(\$ 935.9)\end{array}$ & $\begin{aligned} t & =2.31 \\
\mathrm{df} & =90 \\
p & =0.02\end{aligned}$ \\
\hline
\end{tabular}




\begin{tabular}{|c|c|c|c|c|}
\hline Utilization & Pre-RPM & During-RPM & Post-RPM & Pre to post \\
\hline Emergency visits/1000 member-years & 1013.8 & 633.1 & 573.6 & $X^{2}=6.55, \mathrm{df}=1, p=0.01$ \\
\hline Admissions/1000 member-years & 705.2 & 429.4 & 321.2 & $X^{2}=7.48, \mathrm{df}=1, p<0.01$ \\
\hline Readmissions/1000 member-years & 143.3 & 72.8 & 22.9 & $X^{2}=4.09, \mathrm{df}=1, p=0.04$ \\
\hline
\end{tabular}

gency visits and admissions (Table 5). Five out of six gender-age group cohort comparisons showed either a reduction in the readmission rate or persistence at no readmissions; the only exception, as for the other types of utilization, was that females ages 65-79 experienced a small (nonsignificant) increase in readmissions.

\section{Volume of alerts}

The number of participants with no alerts for systolic or diastolic BP increased sharply from the first to the last month of RPM ( $p<0.0001$ for systolic BP; $p=0.003$ for diastolic BP). On the other hand, the number of participants with no weight alerts decreased: 10 fewer partici- pants had no weight alerts in the last month than in the first month of RPM; however, this trend did not reach statistical significance (Table 6).

\section{Survey findings}

Results of the telephonic survey showed that most participants were satisfied with the RPM program. In fact, in response to an open-ended question, many expressed a preference for being in a monitoring program. Self-perceived health status improved while participants were in the program, with $97 \%$ of participants reporting that their health improved or stayed the same after graduating from RPM. Self-effi-

Table 3. Emergency Visits per 1000 Member-Years, for Pre-Monitoring, Monitoring, and Post-Monitoring Periods, by Gender and Age Group

\begin{tabular}{|c|c|c|c|c|c|}
\hline $\begin{array}{l}\text { ED visits per } \\
1000 \text { member-years }\end{array}$ & $\mathrm{N}$ & Pre & During & Post & Pre to post \\
\hline \multicolumn{6}{|l|}{ Males } \\
\hline 50-64 & 9 & 1000.0 & 779.2 & 0.0 & $\begin{aligned} \mathrm{X}^{2} & =4.50 \\
\mathrm{df} & =1 \\
p & =0.034\end{aligned}$ \\
\hline 65-79 & 25 & 840.0 & 583.3 & 328.8 & $\begin{aligned} \mathrm{X}^{2} & =3.18 \\
\mathrm{df} & =1 \\
p & =0.075\end{aligned}$ \\
\hline $80-92$ & 14 & 1142.9 & 617.6 & 900.0 & $\begin{aligned} \mathrm{X}^{2} & =0.25 \\
\mathrm{df} & =1 \\
p & =0.617\end{aligned}$ \\
\hline \multicolumn{6}{|l|}{ Females } \\
\hline $50-64$ & 5 & 1400.0 & 766.0 & 0.0 & $\begin{aligned} \mathrm{X}^{2} & =2.68 \\
\mathrm{df} & =1 \\
p & =0.102\end{aligned}$ \\
\hline $65-79$ & 19 & 480.0 & 388.2 & 560.7 & $\begin{aligned} \mathrm{X}^{2} & =0.08 \\
\mathrm{df} & =1 \\
p & =0.777\end{aligned}$ \\
\hline 80-92 & 19 & 1578.9 & 840.3 & 1061.9 & $\begin{aligned} \mathrm{X}^{2} & =1.20 \\
\mathrm{df} & =1 \\
p & =0.273\end{aligned}$ \\
\hline
\end{tabular}




\begin{tabular}{|c|c|c|c|c|c|}
\hline $\begin{array}{l}\text { Admissions } \\
\text { per } 1000 \\
\text { member-years }\end{array}$ & $\mathrm{N}$ & Pre & During & Post & Pre to post \\
\hline \multicolumn{6}{|l|}{ Males } \\
\hline 50-64 & 9 & 777.8 & 467.5 & 444.4 & $\begin{aligned} \mathrm{X}^{2} & =0.50 \\
\mathrm{df} & =1 \\
p & =0.480\end{aligned}$ \\
\hline $65-79$ & 25 & 560.0 & 361.1 & 82.2 & $\begin{aligned} \mathrm{X}^{2} & =4.63 \\
\mathrm{df} & =1 \\
p & =0.031\end{aligned}$ \\
\hline 80-92 & 14 & 714.3 & 397.1 & 600.0 & $\begin{aligned} \mathrm{X}^{2} & =0.09 \\
\mathrm{df} & =1 \\
p & =0.764\end{aligned}$ \\
\hline \multicolumn{6}{|l|}{ Females } \\
\hline 50-64 & 5 & 1800.0 & 510.6 & 0.0 & $\begin{aligned} \mathrm{X}^{2} & =3.45 \\
\mathrm{df} & =1 \\
p & =0.063\end{aligned}$ \\
\hline $65-79$ & 19 & 320.0 & 388.2 & 448.6 & $\begin{aligned} \mathrm{X}^{2} & =0.28 \\
\mathrm{df} & =1 \\
p & =0.597\end{aligned}$ \\
\hline $80-92$ & 19 & 947.4 & 537.8 & 318.6 & $\begin{aligned} \mathrm{X}^{2} & =3.37 \\
\mathrm{df} & =1 \\
p & =0.066\end{aligned}$ \\
\hline
\end{tabular}

cacy also showed improvement, with $97 \%$ of participants reporting that being in the program made them better able to take care of themselves. Eighty-one percent of participants specifically reported making positive dietary changes as a result of the program, and $100 \%$ of participants reported having an appropriate action plan should a change in weight occur.

\section{DISCUSSION}

Overall PMPM costs decreased significantly between the pre-RPM period, and both the monitoring period and the post-RPM period. The decrease was not statistically significant for either males or females, considered separately, given the small cohort sizes. Nevertheless, each gender experienced the same rate of reduction in costs, approximately $50 \%$.

These cost reductions resulted from significant reductions in each type of utilization studied: emergency visits, inpatient admissions, and readmissions within 60 days. The rates of decrease for these three dimensions of utiliza- tion ranged from a $43 \%$ reduction in the emergency visit rate to a $54 \%$ reduction in the admission rate to an $84 \%$ reduction in the readmission rate.

The findings from this study were consistent with findings from comparable studies. In a randomized controlled trial (RCT) of HF patients researchers found that health outcomes and mortality were improved in the RPM group without an increase in utilization. ${ }^{12}$ Similarly in the study presented, the improvement in health status was not associated with an increase in utilization-rather utilization decreased during the monitoring period and after graduation.

Bondmass et $\mathrm{al}^{13}$ demonstrated clinical and cost-effectiveness of telemonitoring for HF patients, noting a significant $(p<0.001)$ decrease in readmissions, length of stay, and hospital charges as well as an increase in quality of life $(p=0.002)$. In the present study, readmissions also decreased significantly during and after the RPM intervention and quality of life improved with increased self-efficacy.

Considerable research has demonstrated 


\begin{tabular}{|c|c|c|c|c|c|}
\hline $\begin{array}{l}\text { Readmissions } \\
\text { per } 1000 \\
\text { member-years }\end{array}$ & $\mathrm{N}$ & Pre & During & Post & Pre to post \\
\hline \multicolumn{6}{|l|}{ Males } \\
\hline $50-64$ & 9 & 111.1 & 233.8 & 0.0 & $\begin{aligned} \mathrm{X}^{2} & =0.50 \\
\mathrm{df} & =1 \\
p & =0.480\end{aligned}$ \\
\hline 65-79 & 25 & 80.0 & 55.6 & 0.0 & $\begin{aligned} \mathrm{X}^{2} & =0.97 \\
\mathrm{df} & =1 \\
p & =0.325\end{aligned}$ \\
\hline $80-92$ & 14 & 0.0 & 44.1 & 0.0 & NA \\
\hline \multicolumn{6}{|l|}{ Females } \\
\hline $50-64$ & 5 & 1000.0 & 127.7 & 0.0 & $\begin{aligned} \mathrm{X}^{2} & =1.92 \\
\mathrm{df} & =1 \\
p & =0.166\end{aligned}$ \\
\hline 65-79 & 19 & 53.3 & 0.0 & 112.1 & $\begin{aligned} \mathrm{X}^{2} & =0.29 \\
\mathrm{df} & =1 \\
p & =0.590\end{aligned}$ \\
\hline 80-92 & 19 & 210.5 & 100.8 & 0.0 & $\begin{aligned} \mathrm{X}^{2} & =1.98 \\
\mathrm{df} & =1 \\
p & =0.159\end{aligned}$ \\
\hline
\end{tabular}

gender differences in the diagnosis, management, and outcome of $\mathrm{HF}^{15,16,18,19}$; accordingly, the authors anticipated finding gender differences in the effects of RPM on both cost and utilization in this study. However, the examination of declines in utilization by gender and age group showed fairly uniform patterns: there were sharp but generally nonsignificant decreases for each gender-age cohort except for females ages 65-79, who had small, nonsignificant increases. While the small cohort sizes preclude making generalizations with much confidence, it is the overall consistency of the findings across the gender and age compar- isons, rather than any variations, that are most notable.

There were inconsistent findings regarding alerts: while the number of participants with no alerts for systolic or diastolic BP increased significantly from the first to the last month of RPM, there was actually a decrease, albeit nonsignificant, in the number of participants without weight alerts. The two strong BP alert findings suggest that the RPM program promotes behavior change regarding $\mathrm{BP}$ control. If this is the case, significant reductions in the number of alerts to the CEC may not only improve clinician workflow by reducing avoidable phone

\begin{tabular}{|lcccc|}
\hline \multicolumn{5}{|c|}{$\begin{array}{c}\text { Table 6. } \\
\text { Blood Pressure For First and Last Months of Monitoring }\end{array}$} \\
\hline Percentage without alerts & $\begin{array}{c}\text { First month of } \\
\text { RPM }\end{array}$ & $\begin{array}{c}\text { Last month } \\
\text { of } R P M\end{array}$ & $\mathrm{~N}$ & $X^{2}, d f, \mathrm{p}$ \\
\hline No systolic BP alerts & 35 & 86 & 91 & $61.51,1,<0.0001$ \\
No diastolic BP alerts & 73 & 87 & 91 & $8.76,1,0.003$ \\
No weight alerts & 51 & 41 & 91 & $2.15,1,0.142$ \\
\hline \multicolumn{2}{l}{ RPM, remote physiological monitoring. } & & & \\
\hline
\end{tabular}


calls, but also may allow clinicians to devote more time to participants who are most in need of telephonic interventions.

The reductions in utilization and the subsequent cost savings described are most likely the result of positive changes in member behavior, such as daily weight monitoring, adhering to a low salt diet, identifying symptoms of HF and when to call the doctor, and checking BP. In general, members continued these activities after the RPM equipment was removed, indicating that a RPM program may create sustained behavior change among persons with HF.

\section{Study limitations and implications for future study}

Study limitations include issues of sample size, length of follow-up, lack of randomized control and "regression to the mean," a problem inherent in all pre-post studies of DM interventions.

The small sample size reduced the power to identify statistically significant decreases in costs and utilization. The gender-age subgroups were especially small, reducing opportunities for generalizing from those specific results. Analyses from a planned Phase II RPM study, with larger samples of RPM program graduates, will provide greater statistical power and age-gender cohorts of sufficient size to identify differential effects for males and females, for different age groups, and age-gender interactions.

In the present study, the length of time available for follow-up data collection following home monitoring was truncated at six months, with the average time off of remote monitoring being 5.8 months. The Phase II RPM study will evaluate utilization, PMPM costs, and behavior change practices more longitudinally.

The present study lacked randomization and a control group. The Phase II Study will be a randomized, controlled study with matched samples randomly assigned either to the Basic HF DM Program or the Basic HF DM Program plus RPM.

Finally, and perhaps most importantly, there are the questions of whether, and to what degree, the observed decreases in utilization and cost result from regression to the mean, ie, a process where members are targeted for the
DM program and RPM based on exacerbations of $\mathrm{HF}$, and their conditions moderate during the study period for reasons unrelated to DM in general and RPM monitoring in particular. Although no extraordinary measures were taken to control for this phenomenon, an analysis of pre-intervention utilization revealed no extremely high-cost patients in the sample. The Phase II study design will seek to control for regression to the mean thus minimizing potential for overstatement of the effect of RPM on utilization and cost. Additional planned improvements to the Phase II RPM study include: use of "smart" (interactive) patient monitors, development and application of criteria for removing monitors, and studying patient attitudes and attributes that contribute to the success or failure of RPM as a tool for positive health behavior change.

\section{CONCLUSION}

This study is the first to examine the impact of a Remote Physiological Monitoring program after the monitoring period has been completed. With remote monitoring, most members experienced reduced utilization, decreased PMPM costs, and improved self-perceived health status, self-efficacy, and behavior change. The results suggest that RPM, as a component of a traditional DM program, has beneficial effects on participants' lifestyles after the monitoring period has ended: by teaching individuals to associate their behaviors with their resulting health status, sustainable behavior change can be produced. Thus, this research provides evidence supporting the value of designing and implementing RPM programs that are efficient and tailored to participants' needs.

\section{REFERENCES}

1. American Heart Association and American Stroke Association. Heart disease and stroke statistics-2004 update. Available: 〈http://www.americanheart.org/ downloadable/heart/1079736729696HDSStats2004U pdateREV3-19-04.pdf).

2. Overview of the Heart Failure National Project. Available: 〈http://www.cfmc.org/professionals/pro_chf. htm $\rangle$, accessed November 26, 2004. 
3. Health Care Financing Review, 2001 Medicare and Medicaid Statistical Supplement, CMS, April 2003. Available: 〈http://www.cms.hhs.gov/review/supp〉.

4. Young JB, Mills RM. Treatment of decompensated or refractory heart failure: clinical management of heart failure. Available: 〈http://www.medtronic.com/hf/ physician/problem.html, accessed November 22, 2004.

5. Goldstein S. The effect of beta-blockers on morbidity and mortality associated with heart failure. Am J Manage Care 2000;6:S308-S312.

6. Hussey LC, Hardin S, Blanchette C. Outpatient costs of medications for patients with chronic heart failure. Am J Crit Care 2002;11:474-478.

7. American Heart Association and American Stroke Association. Heart disease and stroke statistics-2005 update. Available: 〈http://www.americanheart.org/ presenter.jhtml?identifier $=1928\rangle$.

8. Nohria A, Chen YT, Morton DJ, Walsh R, Vlasses PH, Krumholz HM. Quality of care for patients hospitalized with heart failure at academic medical centers. Am Heart J 1999;137:1028-1034.

9. McAlister FA, Lawson FM, Teo KK, Armstrong PW. A systematic review of randomized trials of disease management programs in heart failure. Am J Med 2001; 110:378-384.

10. Discher CL, Klein D, Pierce L, Levine AB, Levine TB. Heart failure disease management: impact on hospital care, length of stay, and reimbursement. Congest Heart Failure 2003;9:77-83.

11. Whellan DJ, Gaulden L, Gattis W, et al. The benefit of implementing a heart failure disease management program. Arch Intern Med 2001;161:2223-2228.

12. Goldberg LR, Piette JD, Walsh MN, et al. Randomized trial of a daily electronic home monitoring system in patients with advanced heart failure: the weight monitoring in heart failure trial (WHARF). Am Heart J 2003;146:705-712.
13. Bondmass M, Bolger N, Castro G, Avitall B. The effect of physiologic home monitoring and telemanagement on chronic heart failure outcomes. Internet J Adv Nurs Pract 2000;3:2. Available: 〈http://www. ispub.com/journals/IJANP/Vol3N2/chf.htm), accessed March 27, 2000.

14. Louis AA, Turner T, Gretton M, Baksh A, Cleland JG. A systematic review of telemonitoring for the management of heart failure. Eur J Heart Failure 2003; 5:583-590.

15. Evangelista LS, Kagawa-Singer M, Dracup K. Gender differences in health perceptions and meaning in persons living with heart failure. Heart Lung 2001; 30:167-176.

16. Opasich C, DeGiuli F, Majani G, Pierobon A, DeFeo $S$. Heart failure woman: does she make any difference? Ital Heart J 2003;4:4-16.

17. Foy CG, Rejeski WJ, Berry MJ, Zaccaro D, Woodard $\mathrm{CM}$. Gender moderates the effects of exercise therapy on health-related quality of life among COPD patients. Chest 2001;119:70-76.

18. Stromberg A, Martensson J. Gender differences in patients with heart failure. Eur J Cardiovasc Nurs 2003;2:7-18.

19. Heart Failure Society of America (HFSA). Gender differences found in therapy and resource use in patients with new heart failure diagnosis. Presented at the HFSA $8^{\text {th }}$ Annual Scientific Meeting, Toronto, 2004.

Address reprint requests to: Patty Orr, R.N., Ed.D. American Healthways Corp. 3841 Green Hills Village Dr. Nashoille, TN 37215

E-mail: patty.orr@amhealthways.com 